\title{
Binder syndrome: Clinical findings and surgical treatment of 18 patients at the Department of Plastic Surgery in Polanica Zdrój
}

\author{
Piotr H. Drozdowski ${ }^{1, A, D}$, Ireneusz Łątkowski ${ }^{1,2, C}$, Mateusz G. Zachara ${ }^{1, B, E}$, Piotr Wójcicki ${ }^{1,2, F}$ \\ ${ }^{1}$ Plastic Surgery Unit, Specialist Medical Centre, Polanica Zdrój, Poland \\ ${ }_{2}^{2}$ Plastic Surgery Clinic, Wroclaw Medical University, Specialist Medical Center, Polanica Zdrój, Poland \\ A - research concept and design; $B$ - collection and/or assembly of data; $C$ - data analysis and interpretation; \\ $D$ - writing the article; $E$ - critical revision of the article; $F$ - final approval of article
}

\author{
Address for correspondence \\ Piotr Drozdowski \\ E-mail: piotr_drozdowski@wp.pl \\ Funding sources \\ None declared \\ Conflict of interest \\ None declared
}

Received on December 06, 2015

Revised on December 23, 2015

Accepted on March 09, 2016

DOI

10.17219/acem/62123

\section{Copyright}

Copyright by Author(s)

This is an article distributed under the terms of the

Creative Commons Attribution Non-Commercial License

(http://creativecommons.org/licenses/by-nc-nd/4.0/)

\begin{abstract}
Background. Binder syndrome (BS) is an uncommon congenital underdevelopment of the maxilla and nasal skeleton. Other clinical features include a hypoplastic or absent anterior nasal spine; a short, flat nose with short columella; an acute nasolabial angle; a convex upper lip and class III malocclusion.

Objectives. The aim of the study was to outline the major characteristics of BS and to present a variety of surgical treatment methods.

Material and methods. The study included 18 patients treated in the authors' department from 1989 to 2013.

Results. The patients were predominantly women, aged 6 months to 34 years. Nine patients did not present any co-morbidities, but in the other 9 the most common co-morbidities were a unilateral cleft lip and palate, followed by a cleft palate, a bilateral cleft lip and palate, a cleft lip, GERD, gluten intolerance, oligophrenia, goiter and foot malformation. Most of the patients had not been operated on previously. The most common procedure carried out was an iliac crest bone graft. In 4 patients, no procedures other than cleft lip and palate repair were undertaken. In 3 cases a Le Fort I osteotomy was performed to correct the patients' orthognathic status. No major or life-threating complications were noted. In 2 cases, due to a high degree of resorption of bone grafts, multiple secondary grafting of bone, cartilage and deepithelialized skin was necessary to obtain satisfactory results.
\end{abstract}

Conclusions. In BS surgical treatment is the treatment of choice. It results in adequate correction of facial retrusion. However, due to various degrees of bone resorption, the results are not lifelong. No unequivocally superior surgical strategy in BS has been presented so far. Most disagreement among authors is related to the need for and timing of maxillary osteotomy, the choice between bone and cartilage grafting in nose reconstruction and columella lengthening. Although alloplastic materials offer the tempting advantage of fast and simultaneous augmentation of deficient tissues, their use may risk prolonged infections and extrusion, resulting in exacerbations of deformities.

Key words: Binder syndrome, maxillary underdevelopment, bone graft, cartilage graft, resorption 
The first patient who presented Binder syndrome (BS) might have lived in Quarai, New Mexico, in the $14^{\text {th }}$ century (ca. 1375-1450 AD). The skeleton of a female approximately 16-17 years old was described during a repatriation by the Smithsonian Institution National Museum of Natural History. A thorough examination of the skeleton revealed several characteristics indicating that the individual could have been affected by Binder syndrome. ${ }^{1}$

Binder syndrome, also referred to as maxillonasial dysplasia or frontonasal dysplasia, is an uncommon congenital entity characterized by a series of disorders mainly affecting the skeleton of the midface. The features of Binder syndrome were first described by Noyes in 1939, but it was Binder who, 20 years later, first named it as a distinct clinical entity characterized by arhinoid face, distorted nasal bone positions, a hypoplastic or absent anterior nasal spine, a short, flat nose with a short columella, an acute nasolabial angle, a convex upper lip and predominant class III malocclusion resulting from intermaxillary hypoplasia, and whom the syndrome has been named after ever since. ${ }^{2,3}$ A characteristic inclination of the upper incisors is often marked. Other clinical features that are sometimes seen include absent or atrophic frontal sinuses, cervical vertebral disorders and other skeletal malformations, as well as (rarely) mental retardation. ${ }^{4-6}$

Antoneli et al. investigated audiological and brainstem electrophysiological profiles of patients diagnosed with frontonasal dysplasia and they found no abnormalities in the auditory system from the cochlea to the brainstem, while the mild conductive hearing loss found in the patients with BS and a cleft palate was related to the cleft. ${ }^{7}$ Most authors agree that a flat nose and midfacial retrusion are the two most common findings in Binder syndrome. The syndrome is therefore connected with such terms as "dish face", "fossae prenasalis" and "facies scaphoidea”. However, the spectrum of frontonasal dysplasia severity is very wide and in some populations, such as the Japanese or Chinese, the frequency of BS occurrence may be underestimated due to features similar to maxillary hypoplasia among healthy individuals in these populations. $^{5}$

The etiology of BS remains uncertain and evidence regarding the mode of inheritance in Binder syndrome is ambiguous. Based on a study of 60 families, Olow-Nordenram and Valentin proposed that BS is inherited in an autosomal recessive manner with incomplete penetrance or that it is multifactorial. ${ }^{4}$ In contrast, Gross-Kieselstein et al. suggested a dominant mode of inheritance, based on an examination of an affected mother and daughter. ${ }^{8}$ Many authors suggest that exposure to exogenous factors during pregnancy constitutes the main etiologic factor, naming vitamin $\mathrm{K}$ deficiency and vitamin $\mathrm{K}$ antagonist drugs (warfarin, acenocoumarin), anticonvulsive drugs, retinoic acid or birth trauma, leading to a disturbance of the prosencephalic induction center during embryonic growth. ${ }^{5,9}$ Some authors highlight a connection between warfarin- and acenocoumarin-induced coagulation disorders in pregnancy and hemorrhage-induced nasal septum cartilage damage, leading to maxillary growth retardation that continues in the post-natal period. Howe et al. established that prenatal nasal septum growth is maximal in the $6^{\text {th }}$ through $9^{\text {th }}$ weeks of pregnancy. ${ }^{10}$ If this period overlaps with warfarin exposure, it results in warfarin embryopathy as a consequence of the hemmorhagic mechanism described above. Binder syndrome is therefore often regarded as a variant of chondrodysplasia punctata (CDP), characterized by maxillary growth retardation combined with calcified foci in the nasal septum, evidenced by radiograms performed early in life. ${ }^{11,12}$ Holmstrom et al. stated that inhibition of the ossification center at the lateral and inferior border of the pyriform fossa is responsible for the growth retardation that leads to the formation of characteristic features of Binder syndrome. ${ }^{13}$

In an animal model study Noguchi et al. investigated the correlation between transthyretin gene mutation and facial growth retardation. ${ }^{14}$ They concluded that the mutation leads to delayed transthyretin production, which in turn causes massive cell death in the nasal placode. This phenomenon leads to hypoplasia of the frontonasal region. It is significant that transthyretin plays an important role in retinoic acid delivery to the tissues. Both excess and deprivation of vitamin A, which is the precursor of retinoic acid, may lead to abnormal fetal development. ${ }^{15}$

In an extensive study performed on 24 patients diagnosed with Binder syndrome, Keppler-Noreuil et al. presented etiologic findings and associated disorders. ${ }^{6}$ They diagnosed 13 patients with trisomy 21, 2 with trisomy 18 and 1 with mosaic trisomy 21 . In 1 case, vitamin $\mathrm{K}$ epoxide reductase deficiency was found; in another, Stickler syndrome; in another, fetal warfarin syndrome; and one case of Robinow syndrome was detected.

Other ethiologic factors associated with BS are maternal autoimmune disorders such as systemic lupus erythematosus or mixed connective tissue disease. ${ }^{16}$

Olow-Nordenram et al. stated that $44 \%$ of a group of 43 patients presenting BS had malformations of cervical vertebrae, the atlas and axis being the most frequently affected. ${ }^{17}$ Another study revealed that 15 of 28 patients (53.5\%) suffered from cervicospinal and craniospinal anomalies. $^{18}$

Most diagnostic imaging in BS is based on classic lateral cephalograms, which show reduced anterioposterior dimensions of the anterior cranial base and maxilla and class III malocclusion. In recent years, supplementary diagnostic imaging methods such as 3D laser surface scanning have been introduced. ${ }^{19}$

Due to tremendous progress in prenatal diagnostic imaging, it is now possible to detect facial underdevelopment as early as the $21^{\text {st }}$ week of gestation, or even at 14.5 weeks. $^{20,21}$ This also permits prenatal differential diagnosis of BS and other syndromes characterized by 
Table 1. Treatment course of Binder Syndrome patients treated in authors' department

\begin{tabular}{|c|c|c|c|c|c|}
\hline No. & Sex & Age & Comorbidities & Operations & Complications \\
\hline 1 & $f$ & 7 & none & Illiac crest bone graft - nasal dorsum, maxilla & none \\
\hline 2 & m & 2 & $\mathrm{CL}$ & $\mathrm{CP}$ reconstruction - Kilner - Wardill procedure & none \\
\hline \multirow{2}{*}{3} & \multirow{2}{*}{ f } & \multirow{2}{*}{17} & \multirow{2}{*}{$\begin{array}{l}\text { previous allogenic cartilage graft to } \\
\text { dorsum }\end{array}$} & 1) Illiac crest bone graft - nasal dorsum, maxilla & \multirow{2}{*}{$\begin{array}{l}\text { bone graft } \\
\text { displacement }\end{array}$} \\
\hline & & & & 2) Illiac crest bone graft repositioning & \\
\hline 4 & f & 18 & oligophrenia, CP, goitre, feet malformation & bone graft - nasal dorsum, maxilla & none \\
\hline \multirow{2}{*}{5} & \multirow{2}{*}{ f } & \multirow{2}{*}{8} & \multirow{2}{*}{ none } & 1) Illiac crest bone graft - nasal dorsum, columella & \multirow{2}{*}{ none } \\
\hline & & & & 2) Illiac crest bone graft - nasal dorsum & \\
\hline \multirow{3}{*}{6} & \multirow{3}{*}{ f } & \multirow{3}{*}{13} & \multirow{3}{*}{ none } & 1) Nose osteotomy & \multirow{3}{*}{ none } \\
\hline & & & & 2) Illiac crest bone graft - nasal dorsum, columella & \\
\hline & & & & 3) Rib bone graft - nasal dorsum & \\
\hline \multirow{3}{*}{7} & \multirow{3}{*}{ f } & \multirow{3}{*}{0.5} & \multirow{3}{*}{ CLP, gluten intollerance } & 1) $C L$ reconstruction - Randall procedure & \multirow{3}{*}{ none } \\
\hline & & & & 2) CP reconstruction - Veau procedure & \\
\hline & & & & 3) Illiac crest bone graft - maxillary onlay, alveolar fissure & \\
\hline \multirow{2}{*}{8} & \multirow{2}{*}{ f } & \multirow{2}{*}{10} & \multirow{2}{*}{ none } & 1) Illiac crest bone graft - nasal dorsum, columella & \multirow{2}{*}{ none } \\
\hline & & & & 2) Illiac crest bone graft - nasal dorsum & \\
\hline 9 & m & 2 & BCLP, CL operated elsewhere & $\mathrm{CP}$ reconstruction - Veau procedure & none \\
\hline 10 & m & 29 & none & Illiac crest bone graft - nasal dorsum & none \\
\hline \multirow{7}{*}{11} & & & & 1) Le Fort „1,5” osteotomy & \\
\hline & & & & 2) Illiac crest bone graft - nasal dorsum, columella & \\
\hline & & & & 3) auricular cartilage graft - nasal septum support & \\
\hline & m & 22 & $\begin{array}{l}\text { septoplasty }-6 \text { years old } \\
\text { Illiac crest bone graft - } 19 \text { years old }\end{array}$ & 4) rib bone graft - nasal dorsum & $\begin{array}{l}\text { bone graft } \\
\text { resorption }\end{array}$ \\
\hline & & & & 5) rib cartilage graft - nasal dorsum & \\
\hline & & & & 6) dermal deepithelialised graft - nasal dorsum & \\
\hline & & & & 7) columella reconstruction - illac crest bone graft & \\
\hline & & & & 1) Illiac crest bone graft -nasal dorsum, columella, maxilla & \\
\hline 12 & $f$ & 23 & none & 2) Le Fort I osteotomy & none \\
\hline & & & & 3) Illiac crest bone graft - nasal dorsum, septum & \\
\hline & & & & 1) Illiac crest bone graft - piriform aperture & \\
\hline & & & & 2) Illiac crest bone graft - nasal dorsum, columella & \\
\hline 13 & m & 17 & none & 3) Illiac crest bone graft - nasal dorsum & $\begin{array}{l}\text { bone graft } \\
\text { resorption }\end{array}$ \\
\hline & & & & 4) columella plasty - Cronin procedure & \\
\hline & & & & 5) Illiac crest bone graft - nasal dorsum, maxilla & \\
\hline & & & & 1) Le Fort I osteotomy & \\
\hline 14 & $f$ & 23 & GERD & 2) Illiac crest bone graft - nasal dorsum & none \\
\hline & & & & 3) auricular compound graft - columella & \\
\hline 15 & $f$ & 34 & $C P$ & Illiac crest bone graft - nasal dorsum, columella & none \\
\hline 16 & $f$ & 9 & none & Illiac crest bone graft - nasal dorsum, maxilla & none \\
\hline 17 & f & 0.5 & CLP & CL recontruction & none \\
\hline & & & & 1) osmotic expanders CP reconstruction & \\
\hline 18 & $f$ & 2 & CLP & 2) palate secondary procedures & palate fissure \\
\hline
\end{tabular}


mid-facial underdevelopment, such as chondrodysplasia punctata, Robinow syndrome, Aarksog syndrome, Crouzon syndrome, Apert syndrome, achondroplasia, Stickler syndrome and Rudiger syndrome.

Most of the articles presenting Binder syndrome patients treatment include 20 cases or fewer. To date, no more than 250 cases of BS patients have been described in world medical literature. ${ }^{5,3,21}$

\section{Material and methods}

The aim of the study was to outline the major characteristics of Binder syndrome and the variety of surgical treatment methods used with patients operated on in the authors' department and worldwide. Eighteen patients diagnosed with BS and treated at the Plastic Surgery Clinic of Wroclaw Medical University in Polanica Zdrój (Poland) between 1989 and 2013 are presented.

\section{Results}

The patients were predominantly women $(13: 5)$, aged 6 months to 34 years. Nine patients did not present any co-morbidities; the most common co-morbidities noted were unilateral cleft lip and palate (3 patients), followed by cleft palate (2 patients), bilateral cleft lip and palate (1), cleft lip (1), GERD (1), gluten intolerance (1), oligophrenia (1), goitre (1) and malformation of the feet (1). The great majority of the patients $(15 / 18)$ had not been operated on previously. One patient had had an allogenic cartilage graft implanted in the nasal dorsum; one had undergone a septoplasty and illac crest bone graft; another had had primary reconstruction of a cleft lip.

Iliac crest bone grafts were the most common procedure implemented at the authors' department, to correct collapsed nasal dorsa (12 patients). The bone grafts were used either as solid compact bone grafts into the nasal dorsum or as spongious bone grafts to augment underdeveloped maxilla. In 6 cases the procedure was repeated due to graft resorption of varying degrees. In 1 case the need for re-grafting was caused by bone graft displacement in the postoperative period. In 2 cases the re-grafting procedure was performed using rib bone grafts. In 2 cases the degree of graft resorption was high enough to necessitate 3 re-grafting procedures or combined bone and cartilage grafting. In 1 of these cases, considering the high degree of both bone and cartilage graft resorption, a deepithelialized skin graft was used. In 4 patients, due to a low degree of maxillary underdevelopment and the patients' or their parents' preferences, no procedures other than cleft lip and palate repair were undertaken. In 3 cases Le Fort I or "high" Le Fort I osteotomies (socalled "Le Fort 1.5") were performed to correct the patients' orthognathic status. Two patients' columellas were reconstructed, in 1 case by a compound auricular graft, and in the other by the Cronin procedure. The courses of treatment for all 18 patients are summarized in Table 1.

No major or life-threating complications were noted. In 1 case, a palate fissure occurred, which necessitated secondary closure procedures. As mentioned above, in 2 cases, due to a high degree of resorption of bone grafts, repeated grafting of both bone and cartilage, as well as deepithelialized skin, was required to obtain satisfactory results.

\section{Case presentations}

The treatment histories of selected patients operated on in the authors' department are presented in detail below.

\section{Patient 1}

A 17-year-old male presenting mid-facial underdevelopment and nasal bridge lowering was admitted to the department for nasal reconstruction and maxillary augmentation (Fig. 1-3). He had been diagnosed with Binder syndrome at the age of 5 years in another plastic surgery center, and the treatment was prescheduled for when the patient reached postpubertal age. He was first operated on at the age of 18 years, when a calcaneus bone graft was performed in the area of the pyriform aperture and below the nasal wings in order to augment the underdeveloped region and gain support for further stages of surgical reconstruction. After 6 months nasal reconstruction was performed. Two blocks of compact bone were harvested from the iliac crest and sutured together to form an L-shaped bone graft, which was inserted into the nasal dorsum and columella, reconstructing both elements (Fig. 4-6). Due to resorption of the bone graft placed in the nasal dorsum, another dorsal bone graft was performed after 5 years. The next stage consisted in columella soft tissue correction. The final refinement procedure consisted in an iliac crest bone graft into the maxilla and nasal dorsum (Fig. 7-8).

\section{Patient 2}

A female patient treated at the department for maxillonasal underdevelopment and a soft palate cleft underwent primary soft palate reconstruction using the Wardill-Killner technique at the age of 4 years and further nasal reconstruction with the use of bone grafts. In the first stage, at the age of 24 years, the nasal dorsum and columella were reconstructed using an L-shaped bone graft inserted into a subperiosteal pocket. In the postoperative period, abnormal mobility of the graft was noted, followed by its intense resorption. As a result, another bone graft was performed 2 years later. 
Fig. 1-3. Patient 1 before nasal reconstruction and maxillary augumentation

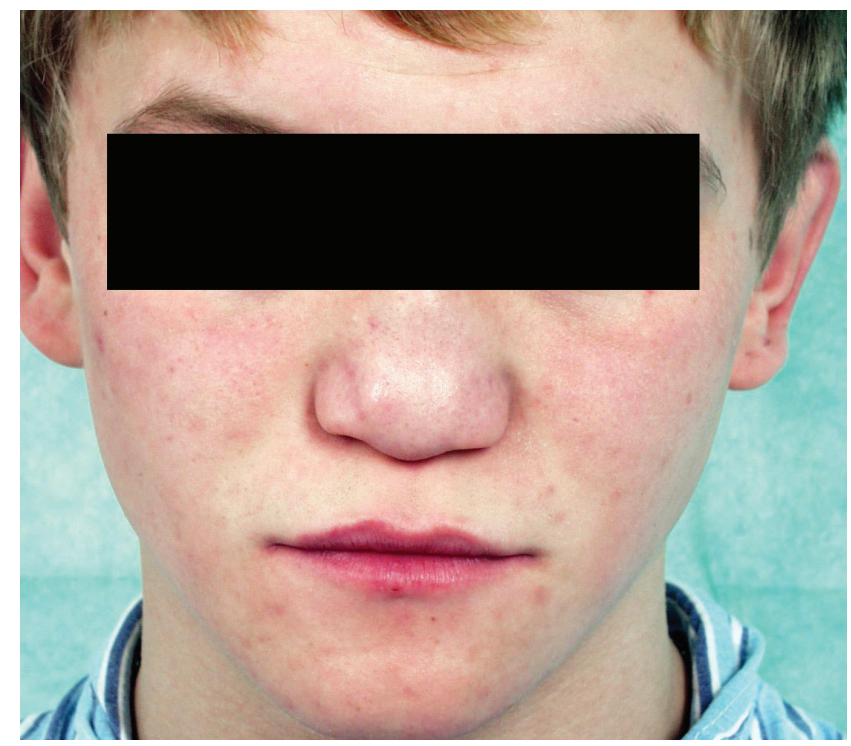

Fig. 1.

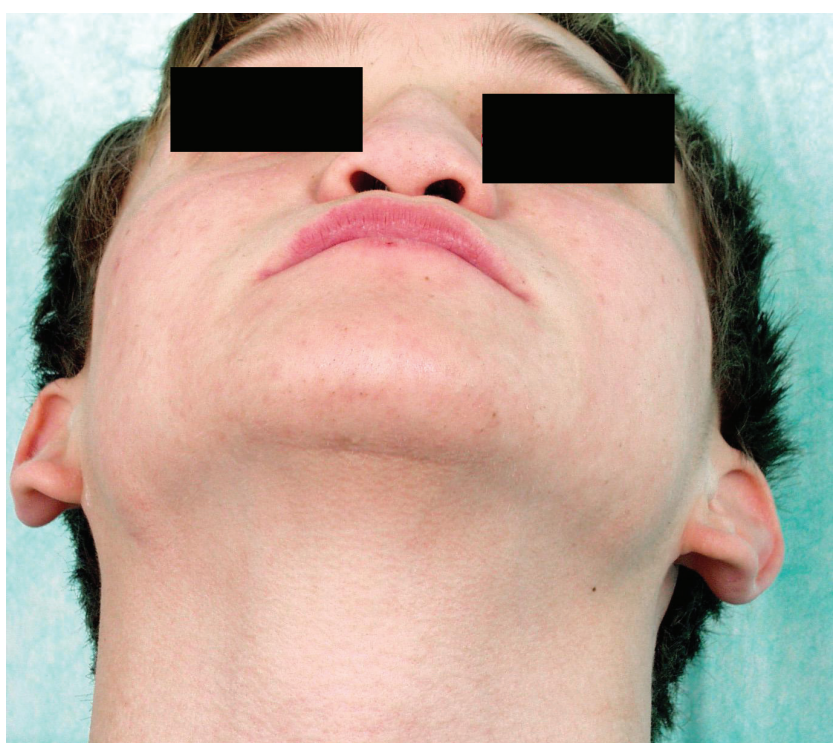

Fig. 2.

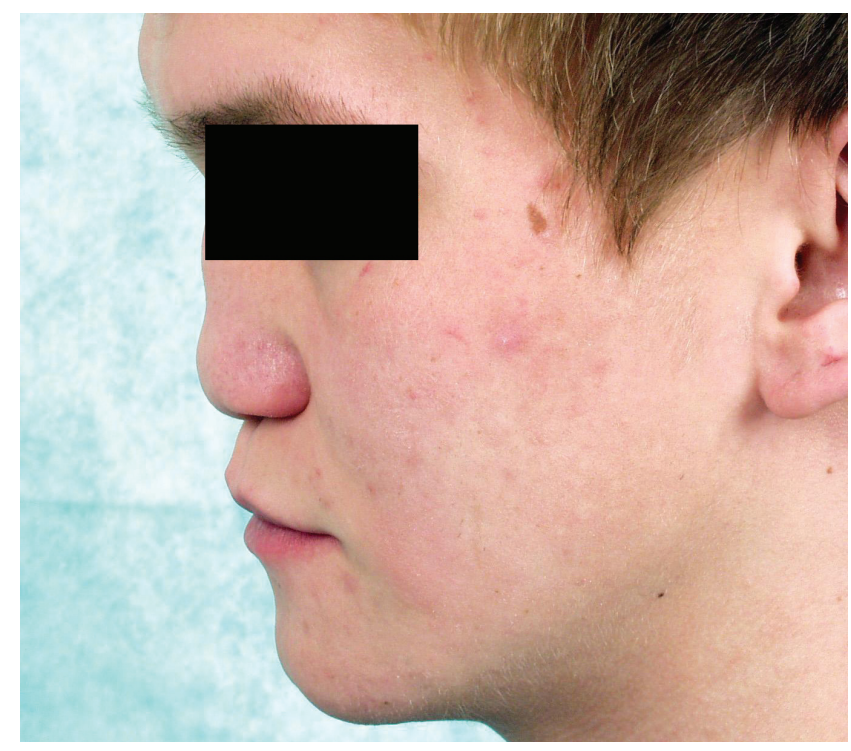

Fig. 4-6. Patient 1 after nasal reconstruction and maxillary augumentation (early result)

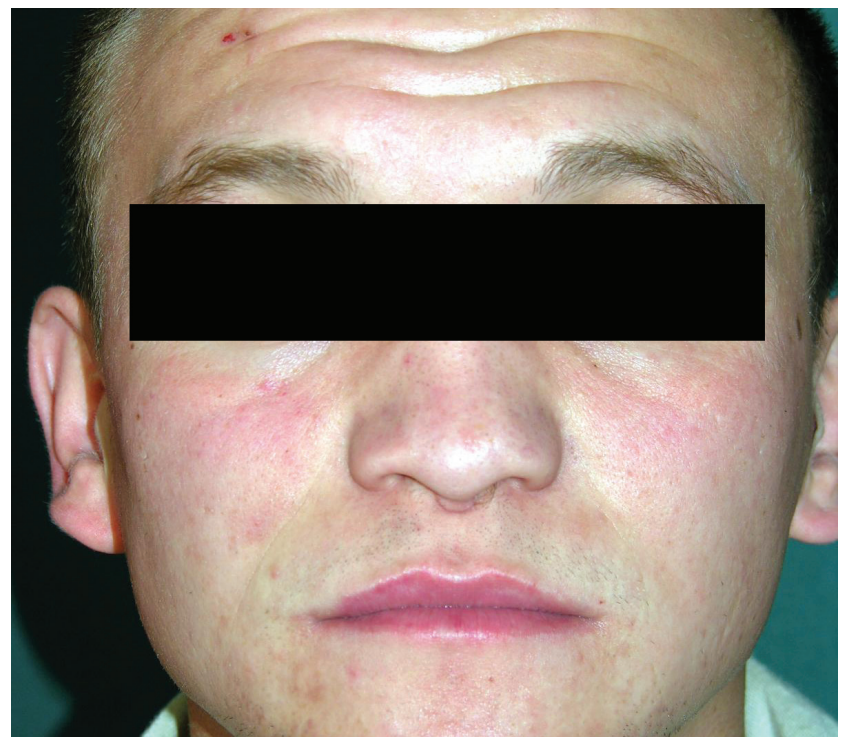

Fig. 4.

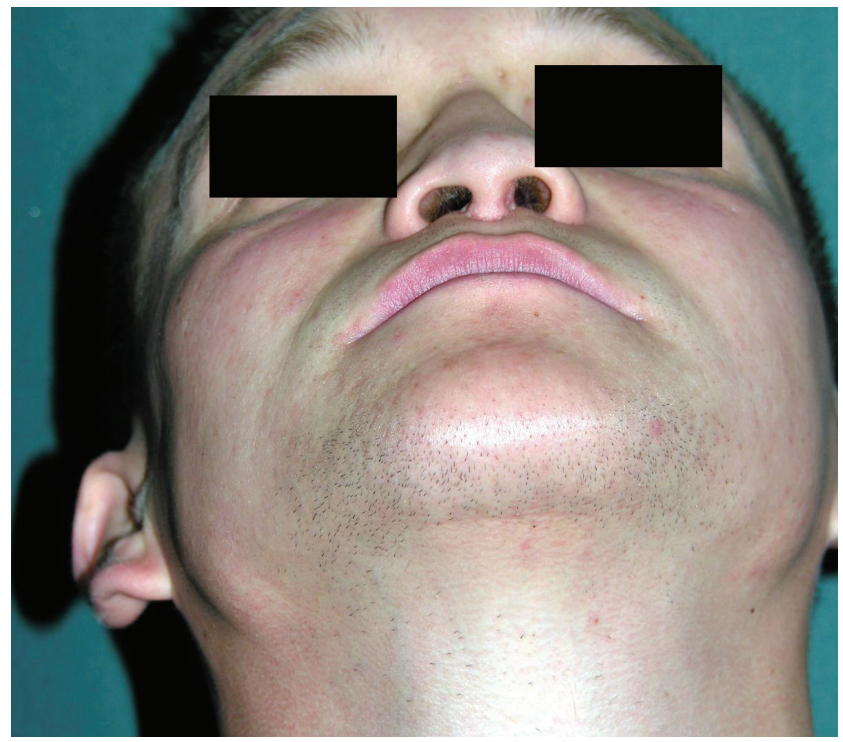

Fig. 5

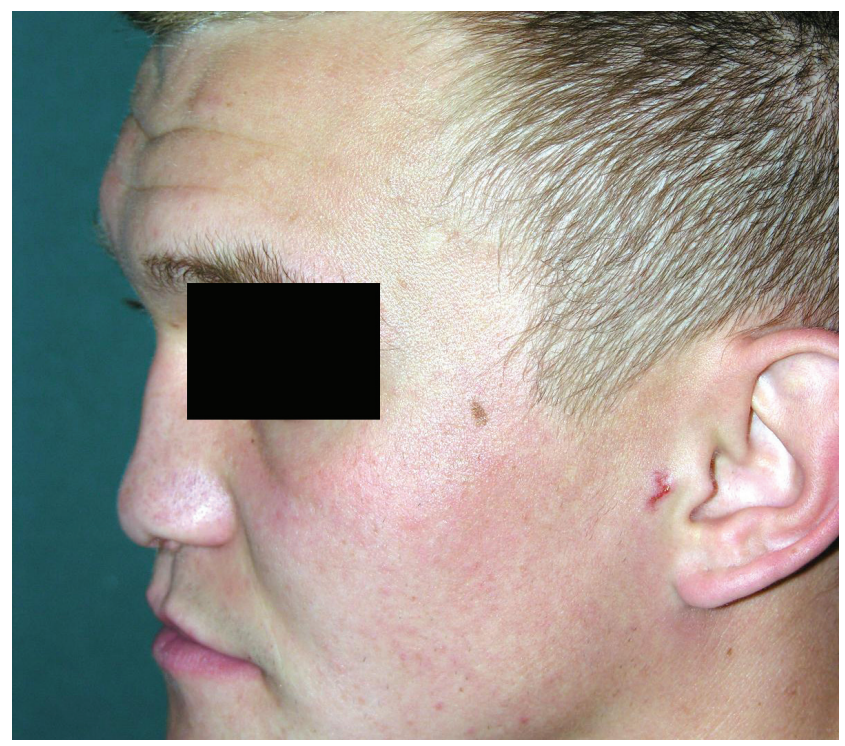

Fig. 6. 
Fig. 7, 8. Distant result after columella soft tissues plasty and refinement procedures

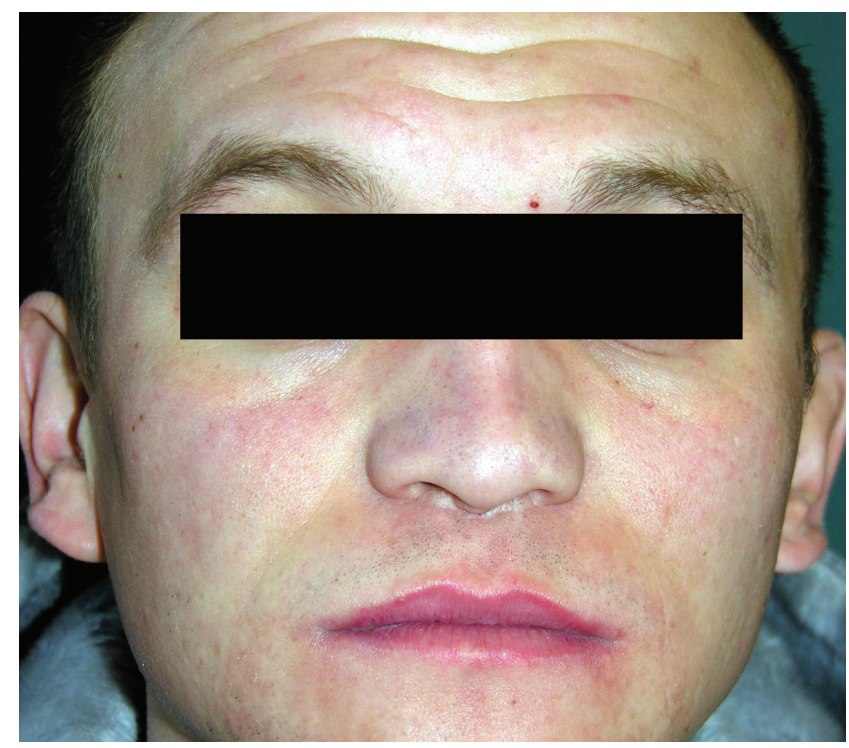

Fig. 7.

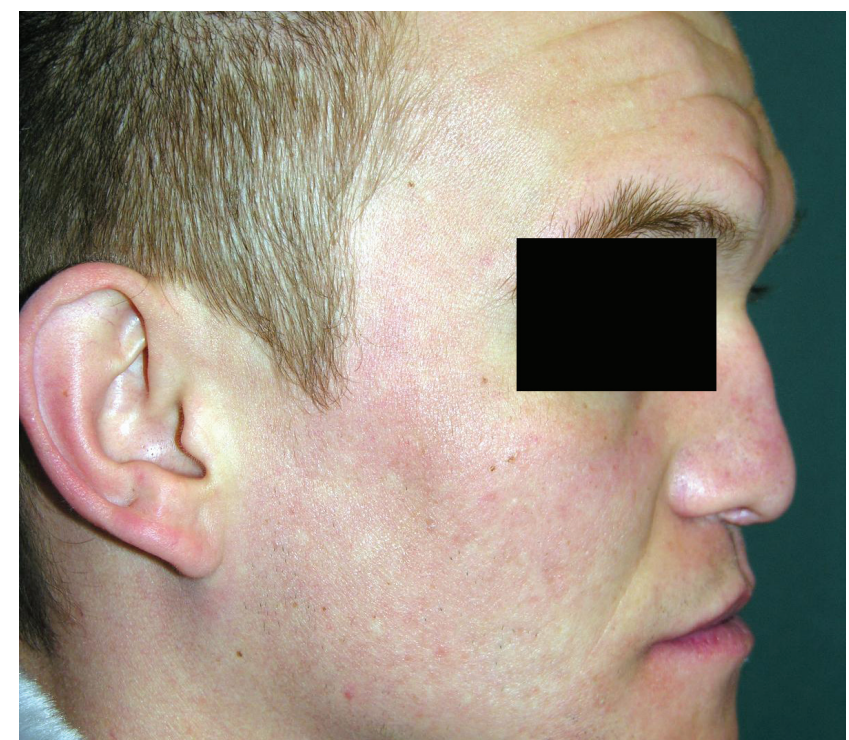

Fig. 8.

\section{Patient 3}

A 21-year-old male patient was admitted to the department for surgical treatment of the underdeveloped middle part of his face. His dominant concern was maxillary retrusion. In order to correct this deformity, as the first stage of surgical treatment a "high" Le Fort I osteotomy was performed. During the next 7 years, he underwent an L-shaped iliac crest bone graft onto the dorsum, columella reinforcement with an auricular cartilage graft, a rib bone graft onto the dorsum and maxilla. In the postoperative period, marked graft resorption occurred, which necessitatd grafting cartilage and deepithelialized dermal grafts in order to achieve long-lasting volume.

\section{Patient 4}

A 23-year-old female patient was admitted to the department presenting the characteristic features of Binder syndrome. Her main concern was the underdevelopment of the nasal dorsum and maxilla. She was scheduled for an illiac crest bone graft to the deficient areas, followed by a Le Fort I osteotomy. Due to bone graft resorption, another bone graft was performed.

\section{Patient 5}

A 17-year-old patient was admitted to the department due to a high degree of nasal dorsum and maxilla underdevelopment (Fig. 9-13). Her surgical treatment consisted in a Le Fort I osteotomy (Fig. 14-19) followed by an iliac crest bone graft onto the dorsum and a composite auricular graft for columella reconstruction (Fig. 20-22).

\section{Discussion}

Although Binder syndrome is not a life-threatening entity nor it does compromise any important organs or systems, it contributes to major face dysmorphia resulting in an impaired social life, leading to a significant decrease in the quality of life. Therefore, patients presenting all or some characteristics of the syndrome require sophisticated surgical procedures to mask the syndrome's effects.

Surgical treatment is the treatment of choice in Binder syndrome. However, no unequivocally superior surgical strategy has been presented so far. In some instances, adequately planned and staged orthodontic treatment may produce good results, which can be further improved by performing a surgical procedure of limited extent, Cosselu et al. describe a Binder syndrome patient treated mainly by staged orthodontic procedures (transverse palate expansion, the use of a Delaire mask, as well as transverse and sagittal maxillary expansion), which produced excellent results in terms of angle class and maxillary underdevelopment correction. ${ }^{22}$ When the patient was 17 , the outcome was further improved with a costal chondral graft to reconstruct the nasal dorsum. As a result, the patient hardly shows any signs of Binder syndrome at all.

Among the clinical features of Binder syndrome, maxillary hypoplasia and nasal skeleton underdevelopment are the most frequently addressed and corrected, enabling the best results to be achieved, and thus leading to improvement in the patients' appearance and the quality of their social life. Most authors perform maxillary osteotomies, bone or cartilage grafting, as well as local skin grafts to obtain maxillary advancement, nasal reconstruction and expansion of deficient soft tissues, respectively.

A certain degree of controversy exists about the need for and timing of a maxillary osteotomy in Binder syndrome. 
Fig. 9-13. Patient 5 presenting high degree of nasal and maxillary underdevelopement

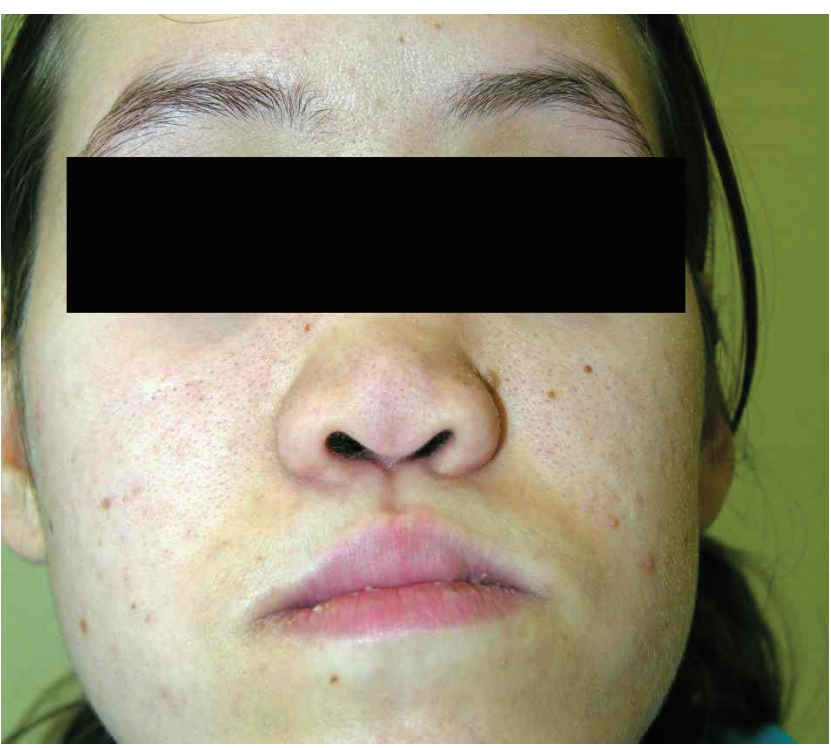

Fig. 9.

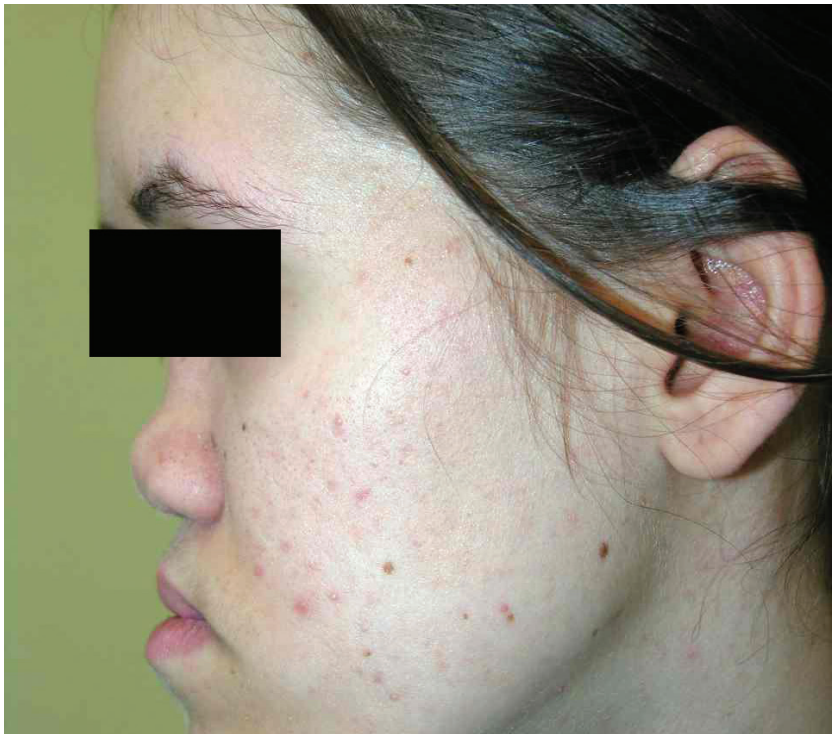

Fig. 10.

Based on 17 years of experience treating 24 cases of Binder syndrome at Chang Gung Memorial Hospital, Goh et al. stated that maxillary osteotomies were rarely required and were therefore reserved only for the patients with severe class III malocclusion that cannot be adequately treated using of orthodontic measures, whereas in other patients augmentation of the maxillary area by means of bone or cartilage grafts is sufficient. ${ }^{23}$ The need for early osteotomies and other surgical procedures, such as bone or cartilage grafting, may be advocated for psychological reasons and the patient's desire for a normal appearance. Although some authors state that early, repeated bone or cartilage grafting may result in progressive midfacial expansion, others postpone aggressive surgical procedures until midfacial growth is completed, which usually oc-



Fig. 11.

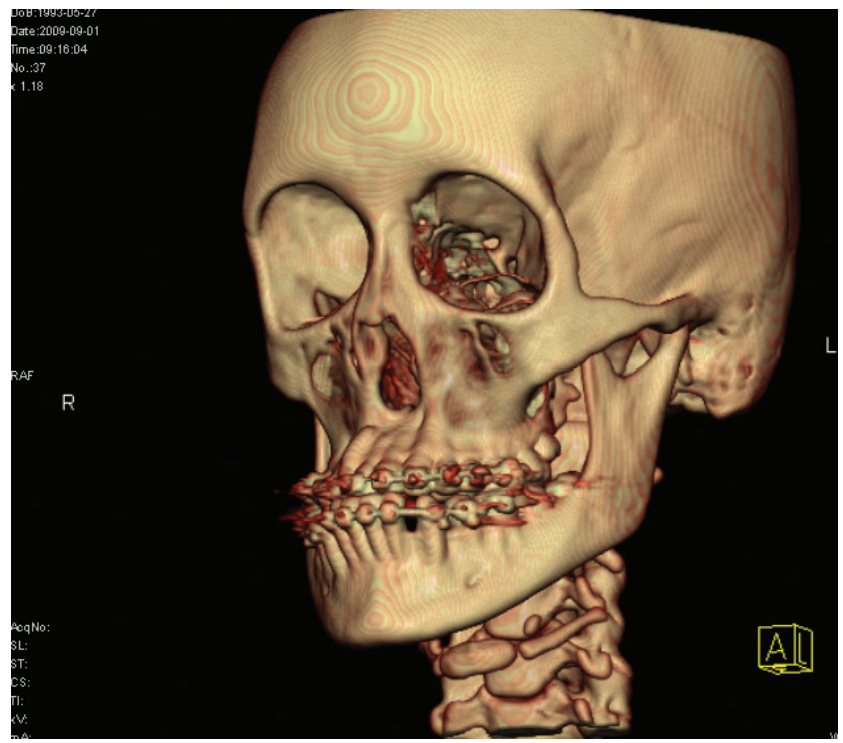

Fig. 12.

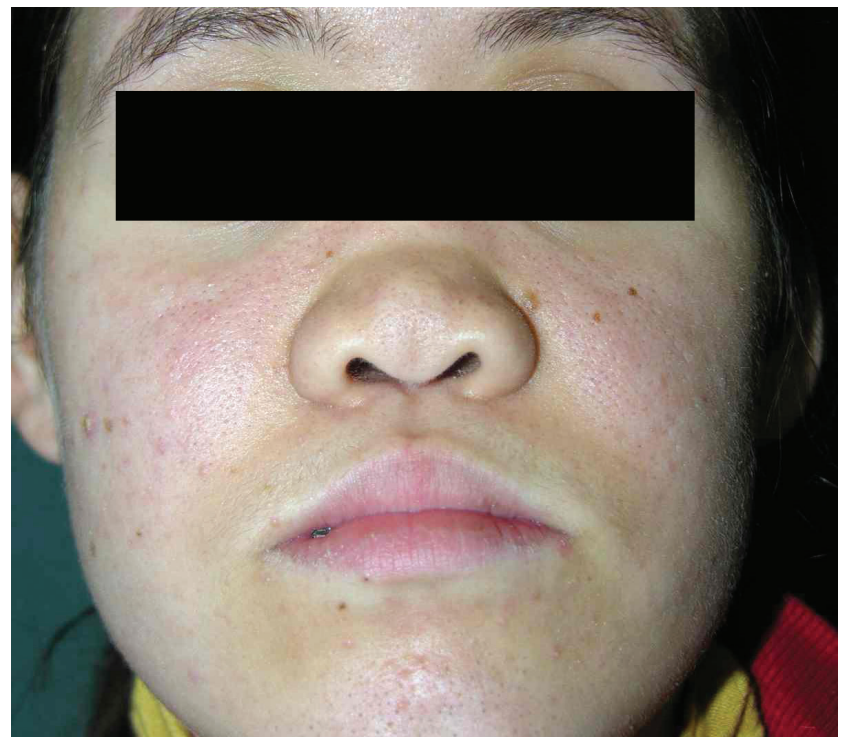

Fig. 13. 
curs in the mid-teenage years. ${ }^{23,24}$ Reconstructive procedures mostly involve augmentation of the pyriform and nasal base region with autologous costal cartilage grafts and, in cases when treatment was necessary before midfacial growth was fully completed, with silastic implants.

The need for columellar skin lengthening has also been a subject of discussion. Tessier stated that the nasal skin may be expanded in short or small noses without any need for grafts or flaps. ${ }^{25}$ Holstrom presented the opinion that in many cases of columella shortening there is no real lack of skin, and that adequate undermining of the skin in that area may result in sufficient stretching of the skin. ${ }^{13}$ On the other hand, many authors advocate local skin plasties in order to achieve columellar skin lengthening. Such procedures can lead to visible scar formation and in some cases serious scar retraction, resulting in further shortening of the columella. ${ }^{26}$

Kruk-Jeromin et al. describe 5 patients presenting characteristics of Binder syndrome, 2 of whom were treated surgically. ${ }^{27} \mathrm{~A}$ V-Y advancement of the columella was performed and an L-shaped bone graft harvested from the iliac crest was inserted into a subdermal pocket in the dorsum and columella. The other patients were treated only orthodontically. The authors stated that in some cases it is sufficient to apply only the aforementioned bone grafts, whereas in other cases maxillary osteotomy is crucial to achieve good results.

Gewalli et al. compared the results of Binder syndrome patients treated using cartilage and bone grafts; both techniques resulted in "an increased and normalized angle of convexity of the face and nasal tip projection". ${ }^{28}$ Goh et al. stated that bone grafts showed a higher rate of resorption, and other authors prefer cartilage over bone for nasal augmentation due to its stability over time. ${ }^{24}$ Bhatt et al. proposed L-shaped costal cartilage grafts for nasal columella and nasal dorsum enhancement, and recommended immersing the graft in a saline solution of gentamicin for $30 \mathrm{~min}$ prior to implantation in order to prevent it from warping. ${ }^{29}$ Chummun et al. described the use of costochondral grafts for reconstructing craniofacial disorders, including 46 cases of Binder syndrome. ${ }^{11}$ They concluded that this kind of procedure resulted in long-lasting correction of underdeveloped noses. Chiang et al. described a 3-dimensional nasal tip, columella, dorsum and alae reconstruction method using a single osseus and cartilaginous rib carved in a special manner to augment all the components of the retruded nose in BS patients. ${ }^{30}$ Monasterio et al. state that the results of bone grafting are unpredictable, especially if the tissue cover remains tight. ${ }^{24}$ They advocate cartilage grafts as the treatment of choice in Binder syndrome nasal reconstruction.

Another method of nasal reconstruction in Binder syndrome was presented by Kansu et al.: A case of a patient treated by placing a titanium screw into the floor of the pyriform fossa, which was supposed to act as the absent nasal spine. ${ }^{31}$ Because the short-term result was regarded as satisfactory by the authors, no long-term follow-up results were reported. This meant that complications such as screw extrusion or injury-related perforation of the nasal tip, which is a risk when using such a method, were not excluded.

In the present study, most of the patients were affected with a cleft lip or palate, which is consistent with other authors' findings. ${ }^{10,32,33}$ In 2002, Mulliken et al. described an entity that they named "binderoid complete cleft lip or palate". ${ }^{32}$ Their patients ( 15 cases) presented cleft lip and/ or palate accompanied by underdevelopment of the nasolabiomaxillary elements. The authors noted that a binderoid phenotype may occur not only in non-syndromic patients, but also in patients with chondrodysplasia punctata, cervical spine anomalies, fetal exposure to warfarin and (as noted above) a cleft lip and palate. The patients presented by Mulliken et al. ${ }^{32}$ were predominantly women $(2: 1)$, which was consistent with the observations of the present authors. This ratio is the reverse of what is observed in cases of isolated cleft lip and palate.

As in other authors' reports, the patients in the present study showed a wide spectrum of intensity of dysmorphic features, ranging from mild nasal hypoplasia to severe nasomaxillary underdevelopment accompanied by malocclusion..$^{13}$

The surgical protocol used at the present authors' institution is based on early closure of the cleft lip/palate in patients presenting this co-morbidity. Nasolabiomaxillary underdevelopment was addressed in adolescence. In the most severe cases, maxillary advancement was performed by means of a Le Fort I or "high" Le Fort I osteotomy. In most patients, nasal dorsum reconstruction was undertaken by illac crest bone graft. The dorsum and columella were reconstructed by an L-shaped bone graft, whereas the maxilla was augmented by using fragments of cancellous bone. The great majority of the patients presented intense resorption of the grafted tissues, requiring another bone graft. In most of the reoperations, auricular cartilage or deepithelialized skin grafts were used. The average number of surgical procedures per patient was 2.2 , which is slightly lower than the 2.4 reported by Chummun et al. ${ }^{11}$ This is a highly satisfactory number, especially considering the high rate of other congenital deformities that were also included in the surgical treatment plan (such as cleft lip and palate). In the authors' opinion, cartilage and dermal grafts show a lower incidence of resorption; this coincides with other authors' observations..$^{11,28-30}$

In the present study, no alloplastic materials were used to augment the nasolabiomaxillary region. Other authors report the use of silicone or high-density porous polyethylene implants in the nasal dorsum and columella..22,34 However, a high rate of complications with alloplastic materials, including extrusion of the implanted material, makes the use of autologous grafts preferable. 
Fig. 14-19. Result after Le Fort I osteotomy

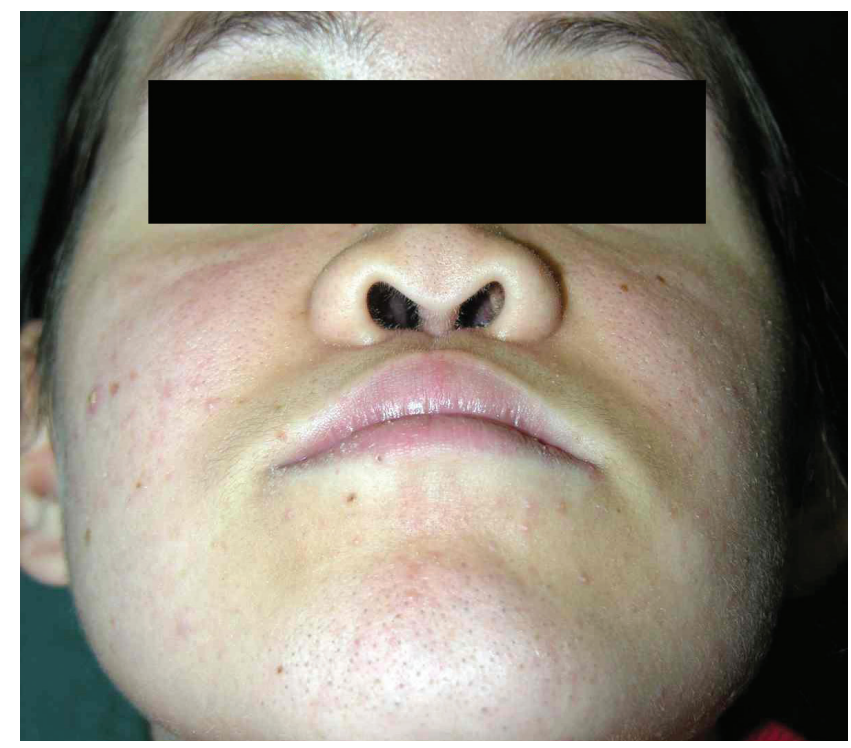

Fig. 14.

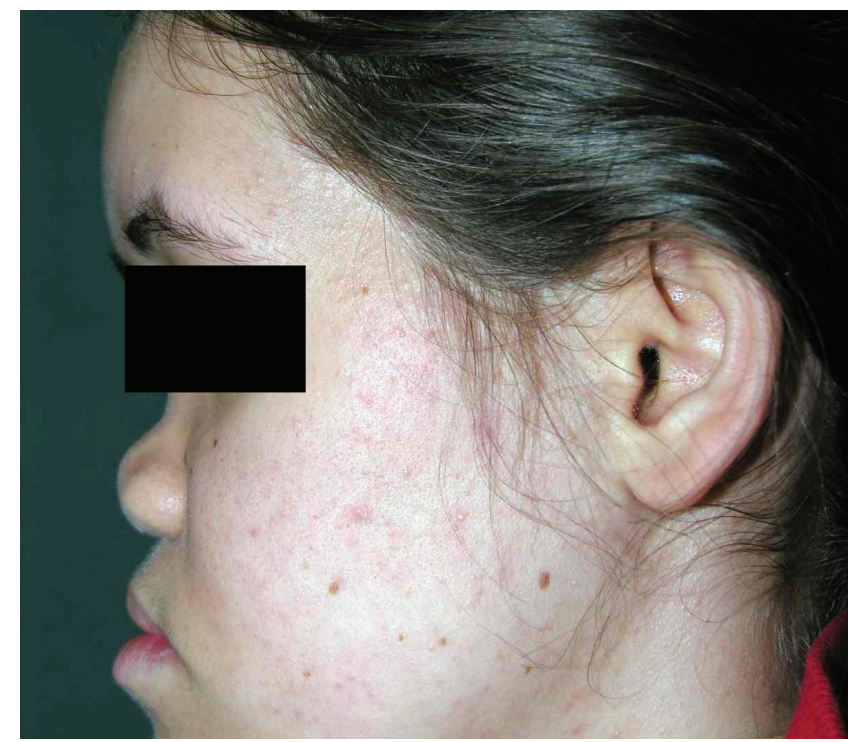

Fig. 15.

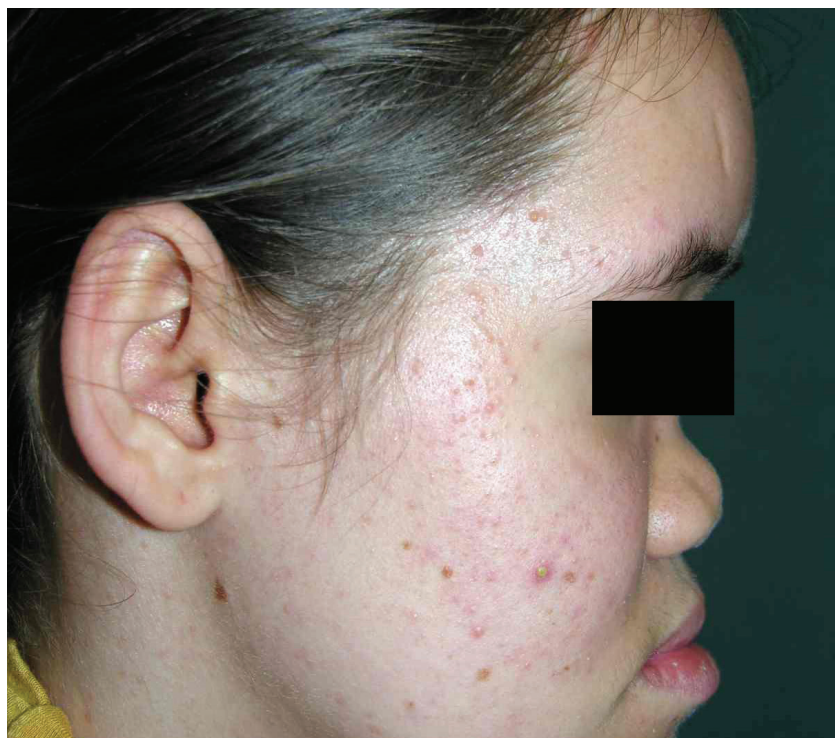

Fig. 16

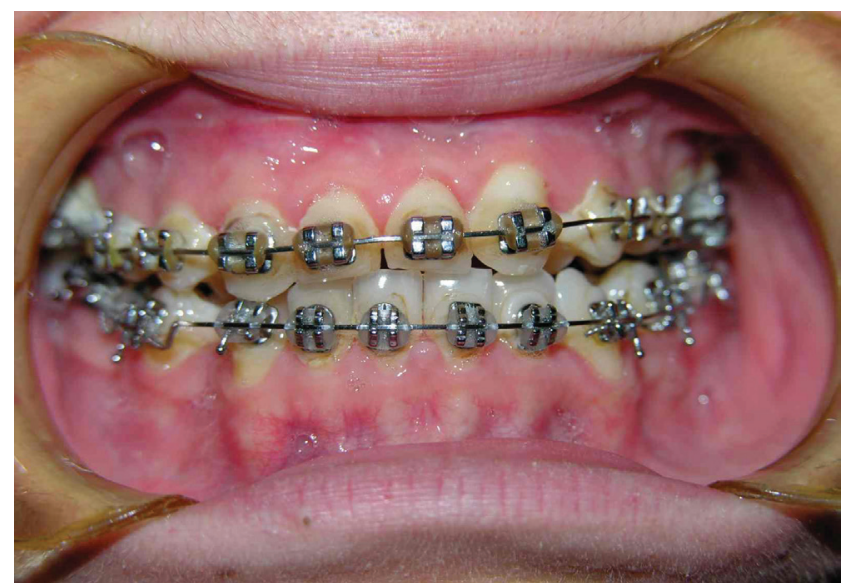

Fig. 17.

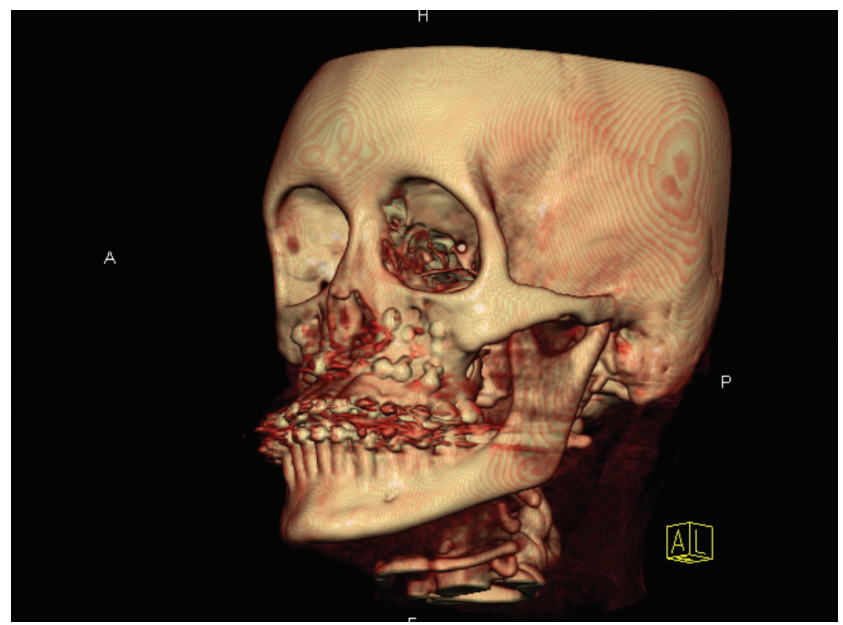

Fig. 18.

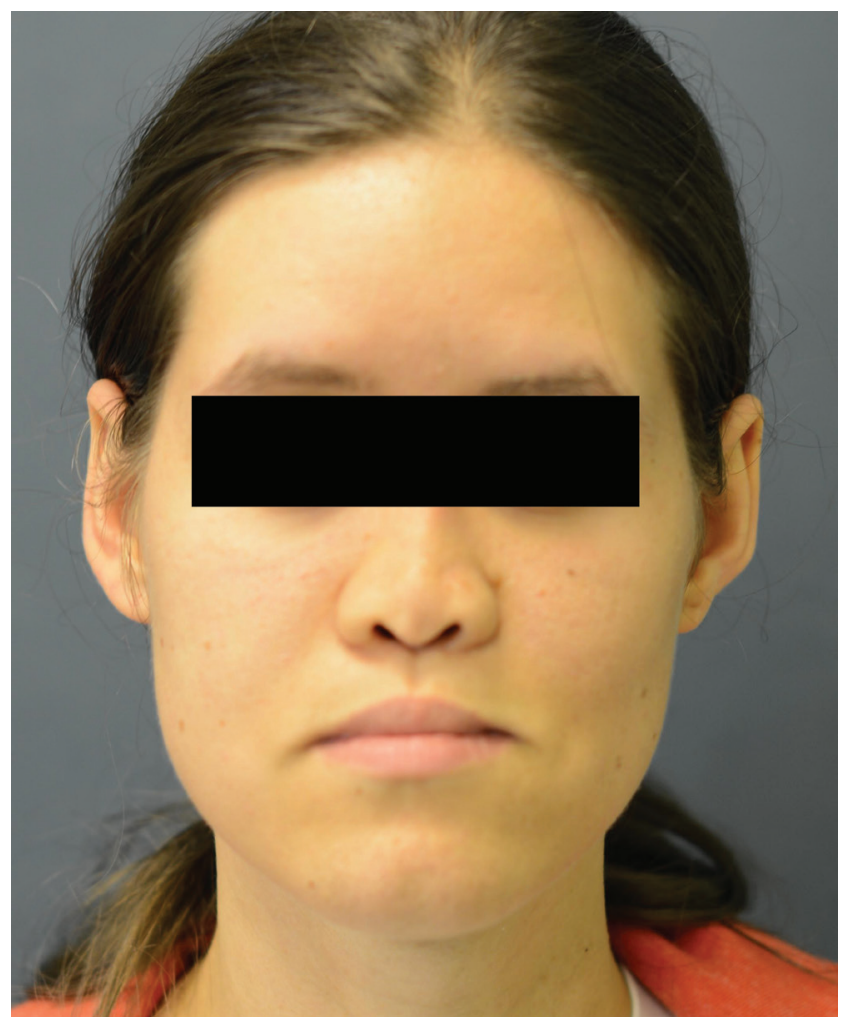

Fig. 19. 
Fig. 20-22. Final result after composite auricular graft for columella reconstruction

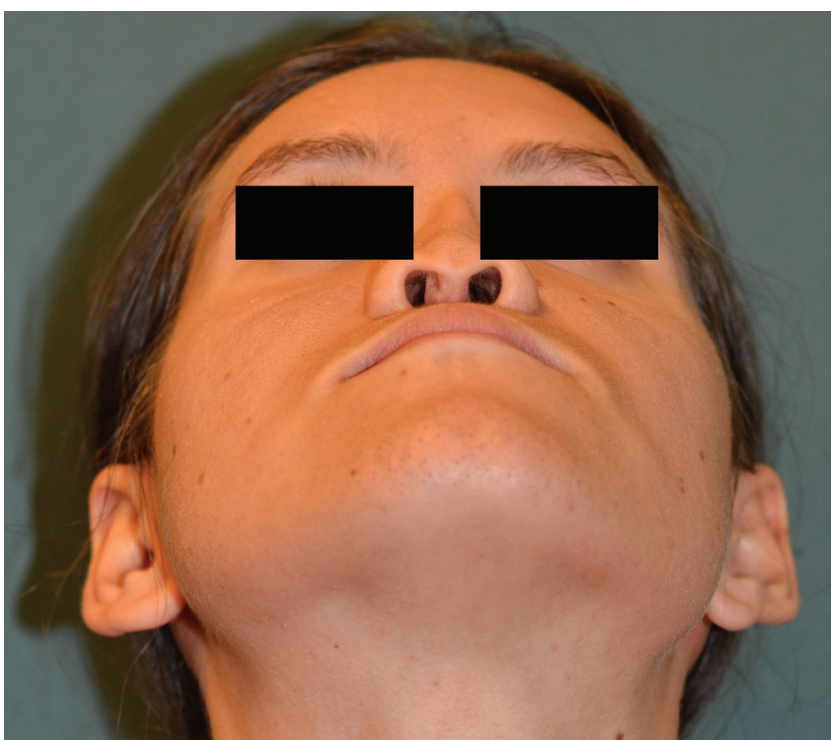

Fig. 20

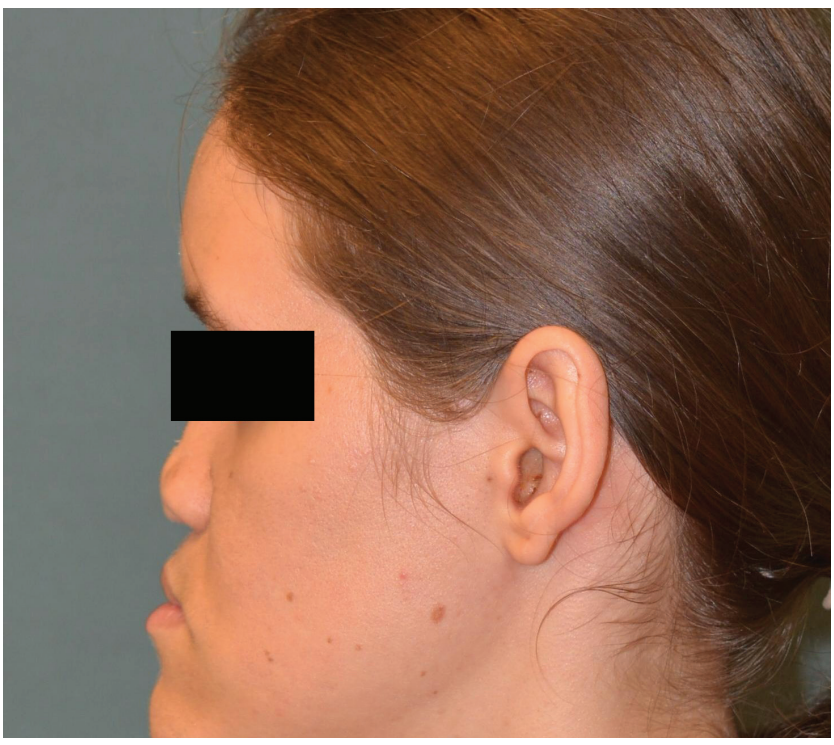

Fig. 21.

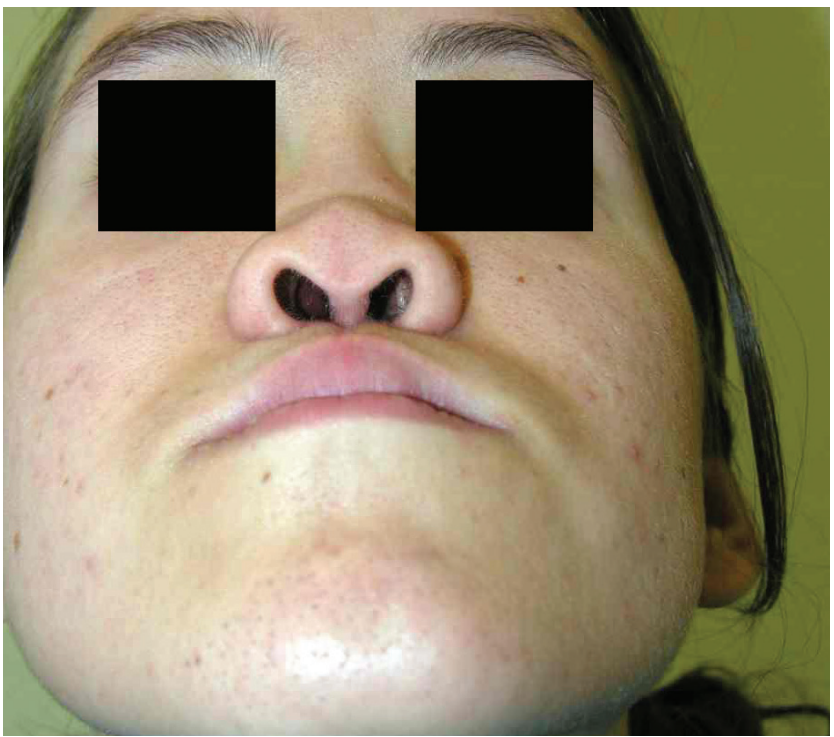

Fig. 22
The patients in the present study were also treated orthodontically, and logopedic rehabilitation was introduced in the early stages.

\section{Conclusions}

In BS, surgical treatment is the treatment of choice, resulting in adequate correction of facial retrusion. However, due to various degrees of bone resorption, the results do not last a lifetime. In some cases they need refinement procedures or even bone re-grafting.

No unequivocally superior surgical strategy in Binder syndrome has been presented so far. Most of the disagreement among authors is related to the need for and timing of maxillary osteotomy, the choice between bone and cartilage grafting in nose reconstruction, and columella lengthening.

Although alloplastic materials offer the tempting advantage of fast and simultaneous augmentation of deficient tissues, their use may risk prolonged infections and extrusion, resulting in exacerbations of deformities.

\section{References}

1. Mulhern DM. Probable Case of Binder syndrome in a skeleton from Quarai, New Mexico. Am J Phy Anthropol. 2002;118:371-377.

2. Noyes FB. Case report. Angle Orthod. 1939;9:160-165.

3. Binder KH. Dysostosis maxilla-nasalis, ein arihnocephaler missbildungscomplex. Deutsch Zahnaerztl Z. 1962;17:438-444.

4. Olow-Nordenram M, Valentin J. An etiologic study of maxillonasal dysplasia - Binder's syndrome. Scand J Dent Res. 1988;96:69-74.

5. Dyer F, Willmot DR. Maxillo-nasal dysplasia, Binder's syndrome: Review of the literature and case report. J Orthod. 2002;29:15-21.

6. Keppler-Noreuil KM, Wenzel TJ. Binder phenotype: Associated findings and etiologic mechanisms. J Craniofac Surg. 2010;21:1339-1345.

7. Antonelli MZ, Giacheti CM, Genaro KF, Zorzetto NL, Richieri-Costa A. Frontonasal dysplasia; clinical evaluation on audiological and brainstem electrophysiological profiles. Braz J Otorhinolaryngol. 2011;77:611-615.

8. Gross-Kieselstein E, Har-Even Y, Navon P, Branski D. Familial variant of maxillonasal dysplasia? J Craniofac Genet Dev Biol. 1986;6:331-334.

9. Howe $A M$, Webster WS, Lipson $A H$, et al. Binder's syndrome due to prenatal vitamin K deficiency: A theory of pathogenesis. Aust Dent J. 1992:37:453-460.

10. Howe AM, Hawkins JK, Webster WS. The growth of the nasal septum in the 6-9 week period of foetal development - Warfarin embryopathy offers a new insight into prenatal facial development. Australian Dental Journal. 2004;49:171-176.

11. Chummun S, McLean NR, Anderson PJ, David DJ. A long-term evaluation of 150 costochondral nasal grafts. J Plast Reconstr Aesthet Surg. 2013;66:1477-1481.

12. Becker MH, Genieser NB, Finegold H, Miranda D, Spackman T. Chondrodysplasia punctata: Is maternal Warfarin therapy a factor? Am J Dis Child. 1975;12:356-359.

13. Holmstrom H. Clinical and pathologic features of maxillonasal dysplasia (Binder's syndrome): Significance of the prenasal fossa on ethiology. Plast Reconstr Surg. 1986;78:559-567.

14. Noguchi H, Kaname T, Sekimoto T, et al. NAso-maxillary deformity due to frontonasal expression of human transthyretin gene in transgenic mice. Genes to Cells. 2002;7:1087-1098.

15. Rothman KJ, Moore LL, Singer MR, Nguyen UDT, Mannino S, Milunsky A. Teratogenicity of high vitamin A intake. N Engl J Med. 1995;333:1369-1373.

16. Schultz SW, Bober M, Johnson C, Braverman N, Jimenez SA. Maternal mixed connective tissue disease and offspring with chondrodysplasia punctata. Semin Arthritis Rheum. 2010;39:410-416. 
17. Olow-Nordenram MA, Radberg CT. Maxillo-nasal dysplasia (Binder syndrome) and associated malformations of the cervical spine. Acta Radiol Diagn (Stockh). 1984;25:353-360.

18. Resche F, Tessier P, Delaire J, Tulasne JF. Craniospinal and cervicospinal malformations associated with maxillonasal dysostosis (Binder syndrome). Head Neck Surg. 1980;3:123-131.

19. Kau $\mathrm{CH}$, Hunter LM, Hingston EJ. A different look: 3-dimensional facial imaging of a child with Binder syndrome. Am J Orthod Dentofacial Orthop. 2007;132:704-709.

20. Cook K, Prefumo F, Presti F, Homfray T, Campbell S. The prenatal diagnosis of Binder syndrome before 24 weeks of gestation: Case report. Ultrasound Obstet Gynecol. 2000;16:578-581.

21. Mc Collum AG, Wolford LM. Binder syndrome: Literature review and long-term follow-up on two cases. Int J Adult Orthodon Surg. 1998;13:45.

22. Cossellu G, Biagi R, Faggioni G, Farronato G. Orthodontic treatment of Binder Syndrome: A case report with 5 years of follow-up. Cleft Palate Craniofac J. 2015;52(4):484-488.

23. Goh RCW, Chen YR. Surgical management of Binder's Syndrome: Lessons learned. Aesth Plast Surg. 2010;34:722-730.

24. Monasterio FO, Molina F, McClintock JS. Nasal correction in Binder's syndrome: The evolution of a treatment plan. Aesthetic Plast Surg. 1997;21:299-308.

25. Tessier P. Aesthetic aspects of bone grafting to the face. Clin Plast Surg. 1981;8:279-301.
26. Hopkin GB. Hypoplasia of the middle third of the face associated with congenital absence of the anterior nasal spine, depression of the nasal bones, and angle class III malocclusion. Br J Plast Surg. 1963;16:146-153.

27. Kruk-Jeromin J, Antoszewski B. Binder's syndrome - symptoms and treatment. Otolaryngol Pol. 2006;40:217-221.

28. Gewalli F, Berlanga F, Monasterion FO, Holmstroem H. Nasomaxillary Reconstruction in Binder syndrome: Bone versus cartilage grafts. A long-term intercenter comparison between Sweden and Mexico. J Craniofac Surg. 2008;19:1225-1236.

29. Bhatt YC, Vyas KA, Tandale MS, Nikhil SP, Bakshi HS, Srivastava RK. Maxilonasal dysplasia (Binder's syndrome) and its treatment with costal cartilage graft: A follow - up study. Indian J Plast Surg. 2008;41:151-159.

30. Chiang CA, Xue K, Gu B, Li Q, Liu K. A novel single-rib recombination method in Binder syndrome treatment. Ann Plast Surg. 2013;70:659-662.

31. Kansu L, Akkuzu B, Avci S. Case report and surgical solution for nasal spine genesis in a woman with Binder syndrome. Eur Arch Otorhinolaryngol. 2008;265:847-849.

32. Mulliken JB, Burvin R, Padwa BL. Binderoid complete cleft lip/palate. Plastic and Reconstructive Surgery. 2003;111(3):1000-1010.

33. Quarrell OWJ, Koch M, Hughes HE. Maxillonasal dysplasia (Binder's syndrome). J Med Genet. 1990;27:384-387.

34. Seyhan T, Kircelli BH, Caglar B. Correction of septal and midface hypoplasia in maxillonasal dysplasia (Binder's Syndrome) using high-density porous polyethylene. Aesth Plast Surg. 2009;33:661-665. 